\title{
LONGITUDINAL ASSESSMENT OF OLDER DRIVERS IN A DMV SETTING
}

\author{
Karlene K. Ball ${ }^{1}$, Daniel L. Roenker ${ }^{2}$, Virginia G. Wadley ${ }^{1}$, Gayla Cissell ${ }^{2}$, Melissa Mathews ${ }^{2}$, \\ David Ball $^{1}$, David Vance ${ }^{1}$, Martha Frankel ${ }^{1}$, Kathy McConnell ${ }^{1}$ \\ ${ }^{1}$ University of Alabama at Birmingham \\ Center for Translational Research on Aging and Mobility \\ Department of Psychology \\ Birmingham, Alabama, USA \\ E-mail: kball@uab.edu \\ ${ }^{2}$ Western Kentucky University \\ Center for Life Span Studies \\ Department of Psychology \\ Bowling Green, Kentucky, USA
}

\begin{abstract}
Summary: A brief battery of functional assessments designed to detect crash risk among older drivers was developed and evaluated initially in 1999 in Maryland motor vehicle licensing sites following the routine vision screening exam. This battery contained a number of cognitive tests (e.g., UFOV ${ }^{\circledR}$ subtest 2 , the closure subtest of the Motor Free Visual Perception Test (MVPT), Trails A and B, cued recall, delayed recall), and several physical measures (e.g., Rapid Pace Walk, Head and Neck Rotation, Foot Tap, Arm Reach). Older adults $(\mathrm{N}=4,173$; mean age $=69$ years) were approached by the staff after license renewal and asked to help evaluate the brief battery. Of the 4,173 older adults approached at the field sites, 2,114 individuals 55-96 years of age participated. Subsequently, the original sample of 2,114 participants was invited to come in once again, during their fiveyear license renewal cycle, and the functional tests were administered once again. To date, 939 individuals have completed the second screening evaluation. An examination of the crash data from the interval between assessments for these individuals indicates that the same cognitive measures are predictive of at-fault crashes. Furthermore, approximately $10 \%$ of those passing the assessment in 1999 are now failing the assessment in 2004. Performance-based cognitive measures are predictive of future at-fault motor vehicle collisions among older adults. Cognitive performance, in particular, is a salient predictor of subsequent crash involvement among older adults. High-risk older drivers can be identified through brief, performance-based measures administered in a DMV setting.
\end{abstract}

\section{INTRODUCTION}

Older drivers are overly represented in crashes and fatalities per mile driven (Evans, 1988a; Williams \& Carsten, 1989), and are more likely to be injured or killed as a result of collision (Evans, 1988b; McCoy, Johnston, \& Duthie, 1989) relative to most other age groups. For injured victims who are hospitalized and recover, the length of hospital stay increases with advanced age (Sartorelli et al., 1999). Thus, the elderly traffic injury victim represents a costly problem in terms of both acute health care costs and the need for continued care. At the same time, the elderly represent the most rapidly growing segment of the driving population in our society, both 
in total number of drivers on the road, and in number of miles driven annually per driver (Transportation Research Board, 1988; Jette \& Branch, 1992). Thus, dramatic increases in traffic fatalities due to age-related driving impairments have been projected over the next quartercentury (Burkhardt, et al., 1998). As the proportion of elderly in the United States population increases, the burden of motor vehicle collisions (MVCs) in the elderly is also likely to expand. Clearly, it is imperative that the factors that place some older drivers at risk be identified, not only to minimize their involvement in motor vehicle crashes and thereby improve public health, but also to foster the development of procedures to identify and place high-risk drivers in appropriate intervention programs.

In an attempt to achieve this goal, a field test of a battery of functional measures was undertaken in 1998 in conjunction with the Maryland Motor Vehicle Administration (MVA). Participants completed a brief (15-minute) battery of cognitive and physical assessments that prior literature had indicated might be related to crash involvement in older drivers. Staplin et al. (2003) described the results of this field test and found that a limited set of elements of the battery were related to crash risk as measured by state records. A subset of the individuals who participated in the 1998 evaluation was re-tested at the time of their license renewal in 2003. A preliminary analysis of the results of that re-evaluation are reported in the present paper.

\section{METHOD}

\section{Participants}

Participants in this study consisted of older adults presenting to renew their driver's license in three MVA field site offices in Maryland (Glen Burnie, Annapolis, Bel Air) between November, 2003 and October, 2004. Individuals who participated in an earlier evaluation (1998-1999) of the screening battery were invited to participate again at the time of their annual license renewal. Approximately 49\% ( $=939)$ of the original sample $(\mathrm{N}=1910)$ agreed to do so. Solicitation to participate was made via a contact letter and phone call from the Maryland MVA. Participants were assured that assessment would (and did) occur after license renewal was completed, and participants were explicitly assured that their performance on the assessment would have no bearing on their driving privileges. Because visual acuity and visual fields were assessed as part of the license renewal process, all participants had at least 20/40 monocular, far-visual acuity (corrected or uncorrected) and a minimum binocular, far-visual acuity of 20/70 as well as continuous field of vision of at least $140^{\circ}$. Participants were paid $\$ 100$ for their participation.

\section{Protocol}

Individuals who agreed to participate were escorted to a different room and informed of the nature of the tests. The battery (described in further detail below) was divided into two parts of approximately equal duration. Part 1 consisted of a battery of physical and cognitive measures described below, and part 2 consisted of subtest 2 of the UFOV ${ }^{\circledR}$ test and a Mobility Questionnaire. The order in which parts 1 and 2 were administered was counterbalanced across participants. 


\section{Physical Measures}

1. Rapid Walk. The participant is asked to walk 10 feet, turn, and return to the starting position. Elapsed time (seconds) for completion of the task is recorded. This task assesses lower limb mobility (Marottoli, et al., 1994).

2. Foot Tap. While remaining seated, the participant is required to touch the floor on alternating sides of a 2 -inch tall barrier 5 times with their right foot. Time (seconds) to complete is measured. This task assesses lower limb mobility (Marottoli et al., 1994).

3. Arm Reach. While seated, participants are asked to raise each of their arms, one at a time, above their head. To pass, each arm must be raised so that the elbow is above shoulder height. This task assesses upper limb mobility (Hu, et al., 1998; Retchin, et al., 1988).

4. Head/Neck Rotation. While seated and wearing a seat belt, participants are instructed to turn their head and identify a high-contrast stimulus (clock face) located on the wall directly behind them at a distance of 10 feet. To pass, the individual must complete the task without rotating the body below the waist. This task measures the head/neck flexibility (Marottoli et al., 1998).

\section{Cognitive Measures}

1. Cued and Delayed Recall. Participants are read three nouns and asked to repeat them. The number recalled correctly on the first attempt and the number of presentations required to achieve correct recall of all three nouns is recorded. After a five-minute interval, participants are instructed to recall the three words. Number correct is again recorded. This task assesses memory (Hu, et al., 1998; McKnight \& McKnight, 1999).

2. Motor Free Visual Perception Test (MVPT), Visual Closure subtest. Participants are given stimuli depicting 4 incomplete figures and one whole figure. Participants select the incomplete figure which, when completed, would match the target figure. Accuracy is recorded as number of errors (maximum $=11$ ). MVPT is a measure of the understanding of spatial relationships, which is important for identifying partially obscured objects (Colarusso \& Hammill, 1972; Tarawneh, et al., 1993).

3. Trails $A \& B$. Participants use a pencil to sequentially connect integers in ascending order (Trails A), or a mix of integers and letters in alternating and ascending order (Trails B) as quickly as possible. Time (seconds) to completion is recorded. Trails is a measure of visual search and sequencing, information processing speed, divided attention, and set flexibility (Reitan, 1958).

4. $U F O V^{\circledR}$ subtest 2. For the sake of brevity, only subtest 2 of the $\mathrm{UFOV}^{\circledR}$ was included in the battery for a four-minute evaluation. This divided-attention task was chosen because it correlates highly with the $\mathrm{UFOV}^{\circledR}$ total score, has been used in previous analyses, is the single subtest that best predicted crash involvement in earlier work, and therefore represents the least sacrifice in predictive power for the benefit of brevity (Owsley et al., 1998). Participants are required to identify a central target and locate a simultaneously presented peripheral target. Display duration is manipulated using a double staircase method until a $75 \%$ correct detection threshold is 
identified. The threshold is reported in msec. The UFOV ${ }^{\circledR}$ test is a measure of the cognitive processing speed required for rapid recognition and response to simultaneous demands in central and peripheral visual fields under varying conditions (Ball \& Owsley, 1991).

\section{Self-reported Mobility}

Mobility Questionnaire. Participants complete a one-page questionnaire assessing employment status, driving exposure (days per week, miles per week, miles per year), driving avoidance (night, bad weather, left turns, high traffic roads, unfamiliar areas, and concerns about ability), and general mobility (e.g., falls within the last 3 years and difficulty walking or climbing stairs).

\section{Outcome Measure}

The primary outcome of interest for this study was the occurrence of an at-fault motor vehicle collision (MVC) in the interval between assessments at the MVA field sites. Crash records were obtained from the Maryland Motor Vehicle Administration database. For each crash incurred by a participant in the study, the licensee's involvement in the crash was determined by the on-thescene police officer as at-fault, not at-fault, or fault unknown. Both at-fault and fault unknown events were included in the dependent measure. To date, crash data are available through December 31, 2004.

\section{RESULTS}

Means and standard deviations on each of the functional measures, as well as demographics of the sample, are presented in Table 1. Since functional performance on the assessment battery was collected at two points five years apart and crash data were available for the interval between assessments, a simple linear interpolation was used to estimate an individual's performance level on each of the functional measures at the time of crash. There were 55 individuals who experienced a state-recorded crash during this interval. For individuals who did not crash during the interval between assessments $(\mathrm{N}=884)$, the estimated score for that individual was interpolated for the midpoint of the interval. For each of the functional measures, a univariate odds ratio was determined using the cutpoints suggested by Staplin et al. in the analysis of the initial screening (1998-1999) sample (Staplin, Gish, \& Lococco, 2003). The results of this analysis are presented in Table 2 along with the comparable odds ratio determined for that measure in the Staplin et al. paper. A review of Table 2 clearly shows that the same set of measures that were predictive of crashes in the interval one year prior and two years post the 1999 assessment were found to be predictive when reassessed on the same sample 5 years later. The only exception to this pattern is that Rapid Pace Walk failed to show a significant relationship to crashes at the five-year renewal. This may be due to the fact that more frail individuals assessed in 1998, ones who would experience difficulty walking 10 feet and returning, may be more likely not to return for license renewal 5 years later. Future analyses will examine this possibility. 
Table 1. Sample demographics and Means (Standard Deviations) for functional measures

\begin{tabular}{|l|c|c|}
\hline MEASURE & $\mathbf{1 9 9 8}$ & $\mathbf{2 0 0 3}$ \\
\hline Age & $67.5(7.4)$ & \\
\hline \% Female & 46.0 & \\
\hline \% Caucasian & 92.7 & $165.9(149.7)$ \\
\hline UFOV & & \\
\hline MVPT & $152.4(144.4)$ & $2.53(2.13)$ \\
\hline Trails B & $1.43(1.59)$ & $115.40(62.85)$ \\
\hline Delayed Recall & $96.63(41.31)$ & $0.61(0.84)$ \\
\hline Rapid Pace Walk & $0.53(0.79)$ & $6.89(2.62)$ \\
\hline
\end{tabular}

Table 2. Odds Ratios for functional measures at two assessment points

\begin{tabular}{|l|c|c|c|}
\hline & & $\mathbf{2 0 0 3}, \mathbf{N}=\mathbf{9 3 8}$ & $\mathbf{1 9 9 8 ,} \mathbf{N}=\mathbf{1 9 1 0}$ \\
\hline MEASURE & CUTPOINT & OR & OR \\
\hline MVPT & 4 errors & $3.03^{*}$ & $2.07^{*}$ \\
\hline & 5 errors & $4.26^{*}$ & $2.84^{*}$ \\
\hline UFOV $^{\circledR}$ & $250 \mathrm{~ms}$ & 1.55 & $1.90^{*}$ \\
\hline & $300 \mathrm{~ms}$ & $2.40^{*}$ & $1.98^{*}$ \\
\hline Trails B & $180 \mathrm{~s}$ & $3.87^{*}$ & $2.15^{*}$ \\
\hline Delayed Recall & 2 errors & $2.97^{*}$ & $1.63^{*}$ \\
\hline Rapid Pace Walk & $9.75 \mathrm{~s}$ & 1.03 & $1.94^{*}$ \\
\hline
\end{tabular}

\section{DISCUSSION}

The data present a very clear pattern. A relatively small set of cognitive and physical measures can be administered by MVA staff with minimal training. This set of measures was found to predict crashes in the interval of time surrounding the initial assessment in 1998 (see Staplin et al., 2003). When a subset of these same individuals was re-tested five years later, again at the time of license renewal, the same set of measures remained effective predictors of crash involvement, despite the fact that those most likely to drop out of the sample due to driving cessation were those with poor functional abilities (particularly those with poor speed of processing as evaluated through $\mathrm{UFOV}^{\circledR}$ test performance). Clearly the data demonstrate that these measures capture a set of skills which are related to successful driving performance and that such a battery can be easily administered in a field setting.

\section{ACKNOWLEDGMENTS}

This research program is funded by NIA Grants 5P30 AG022838 and 5R01 AG021958 (Edward R. Roybal Center for Research on Applied Gerontology). Drs. Ball and Roenker own stock in Visual Awareness Inc., which owns the patent for UFOV ${ }^{\circledR}$ testing and training software. 


\section{REFERENCES}

Ball, K., \& Owsley, C. (1991). Identifying correlates of accident involvement for the older driver. Human Factors, 33(5): 583-595.

Burkhardt, J., Berger, A., Creedon, M., \& McGavock, A. (1998). Mobility and independence: Changes and challenges for older drivers. Ecosometrics, Inc., for the Coordinating Council on Mobility and Access. The U.S. Department of Human Services and Traffic Safety Administration.

Colarusso, R. P., \& Hammill, D. D. (1972). Motor-Free Visual Perception Test. Los Angeles, California: Western Psychological Services.

Evans, L. (1988a). Older driver involvement in fatal and severe traffic crashes. Journal of Gerontology, 43: S186-193.

Evans, L. (1988b). Risk of fatality from physical trauma versus sex and age. The Journal of Trauma, 28: 326-327.

Hu, P. S., Trumble, D. A., Foley, D. J., Eberhard, J. W., \& Wallace, R. B. (1998). Crash risk of older drivers: A panel analysis. Accident Analysis and Prevention, 30(5): 569-582.

Jette, A. M., \& Branch, L. G. (1992). A ten-year follow up of driving patterns among the community dwelling elderly. Human Factors, 34: 25-31.

Marottoli, R. A., Cooney, L. M., Wagner, D. R., Doucetter, J., \& Tinetti, M. E. (1994). Predictors of automobile crashes and moving violations among elderly drivers. Annals of Internal Medicine, 121: 842-846.

Marottoli, R. A., Richardson, E. D., Stowe, M. H., Miller, E. G., Brass, L. M., Cooney, L. M., Jr., \& Tinetti, M. E. (1998). Development of a test battery to identify older drivers at risk for self-reported adverse driving events. Journal of the American Geriatrics Society, 46: 562-568.

McCoy, G. F., Johnston, R. A., \& Duthie, R. B. (1989). Injury to the elderly in road traffic accidents. The Journal of Trauma, 29: 494-497.

McKnight, A. J., \& McKnight, A. S. (1999). Multivariate analysis of age-related driver ability and performance deficits. Accident Analysis and Prevention, 31: 445-454.

Owsley, C., Ball, K., McGwin, G. J., Sloane, M. E., Roenker, D. L., White, M. F., \& Overley, E. T. (1998). Visual processing impairment and risk of motor vehicle crash among older adults. JAMA: The Journal of the American Medical Association, 279(14): 1083-1088.

Reitan, R. M. (1958). Trail Making Test: Manual for administration, scoring and interpretation. Indianapolis: Department of Neurology, Indiana University Medical Center.

Retchin, S. M., Cox, J., Fox, M., \& Irwin, L. (1988). Performance-based measurements among elderly drivers and non-drivers. Journal of the American Geriatrics Society, 36: 813-819.

Sartorelli, K. H., Rogers, F. B., Osler, T. M., Shackford, S. R., Cohen, M., \& Vane, D. W. (1999). Financial aspects of providing trauma care at the extremes of life. The Journal of Trauma, 46(3): 483-487.

Staplin, L., Gish, K., \& Lococco, K. (2003). Model driver screening and evaluation program. National Highway Traffic Safety Administration, Technical Report (U.S. DOT/NHTSA Contract DTNH22-96). 
Tarawneh, M. S., McCoy, P. T., Bishu, R. R., \& Ballard, J. L. (1993). Factors associated with driving performance of older drivers. Transportation Research Record, 1405: 64-71.

Transportation Research Board (1988). Transportation in an Aging Society, Vol. 1.

Williams, A. F., \& Carsten, O. (1989). Driver age versus crash involvement. American Journal of Public Health, 79(3): 326-327. 